\title{
The Causality Relationship between Hnx Index and Stock Trading Volume in Hanoi Stock Exchange
}

\author{
Vuong Quoc Duy, Le Long Hau
}

\author{
${ }^{1}$ Associate Professor in Economics, College of Economics, Can Tho University, Vietnam \\ ${ }^{2}$ Doctor in Economics, College of Economics, Can Tho University, Vietnam
}

\begin{abstract}
This paper examines the casual relations between the market return and trading volume for the $\mathrm{Ha}$ Noi Stock Exchange during the period from May $3^{\text {th }}, 2013$ to March $2^{\text {rd }}$, 2016. This paper uses Granger test and the results showed that the change of the volume of transactions that affect the change of HNX-Index. On the basis of this conclusion, we shall determine the degree of influence of the change in trading volume with HNX-Index by means of regression analysis.
\end{abstract}

Keywords-Ha Noi Stock Exchange, market index trading volume relations, Granger causality test.

\section{INTRODUCTION}

It has been more than 19 years of the development of Vietnam securities industry since the event of the State Securities Commission was established under Decree $75 /$ ND-CP of the Government dated on $28^{\text {th }}$ November 1996 , the stock market has become an important channel for capital mobilization of the economy industry.The launch of Vietnam stock market is a great opportunity for investors to participate in. In fact, it is not only a channel to mobilize domestic investors but also attracts foreign investors and the international economic groups. However, in recent years, especially in 2015 , the stock market witnessed intense vibration sessions of two main indexes affected by the external factors. In 2016, the impact of the economic and political world is not decrease but likely increase. Therefore, to participate in the stock market effectively in order to generate the highest profitability, investors should have certain knowledge about the stock market and essential information about it. Thus, information plays an important role in stock market. In other words, information is central element to assess the effectiveness of market. When the information use and reflect are faithfully, the market is considered an effective one in terms of information. Transparent information on the stock market will help investors a lot to be able to make right decisions.
And one of the things that investors are particularly interested in is the volume of shares traded. This is one of motivations to create the change of stock price. In case of the number of shares sold for hedging purposes will generate inverse relationship with profitability. On the other hand, the number of shares sold for speculative reason will generate positive relationship with future profit.

In recent years, the relationship between the stock price and trading volume has been extensively studied in many countries. Most of studies focussed on various relationships between the price and volume of stocks. Firstly, There is a two ways relationship between stock price and trading volume; Secondly, the trading volume has influenced on the valuation of stocks; Thirdly, the stock price changes leads to the transaction volume and Lastly, there is not relationship between price and volume of stocks.

As far as concerned, although the relationship between stock price and trading volume has been studied a lot in recent decades, no study is conducted in the case of Ha Noi Stock Exchange of Vietnam. It is significantly to investigate the relationship between the market price index HNX Index and the volume of shares traded on the Hanoi Stock Exchange".

\section{RATIONALE AND METHODOLOGY 2.1 Rationale 2.1.1 Calculation of the HNX-Index}

HNX Index is calculated and published firstly on the officially opened day of the first session of the market (dated 14.07.2005), known as the time of the original. The index calculates the price movement of all stocks traded on the Hanoi Stock Exchange. The method calculating the index is the ratio of total current market value to the total market value of listed shares at the time of the original. Specifically at the time of the original, the index has a value of 100 . 
Calculation method:

The formula for calculating market index:

HNX Index

$=\frac{\text { The total of current market value (GTn) }}{\text { The total of market value of the original (GTo) }} \times 100$

Or

$$
\text { HNX Index }=\frac{\Sigma \text { Pit } * \text { Qit }}{\sum \text { Pio } * \text { Qit }} \times 100
$$

\section{Explaination:}

Pit: The market value of the share i at the moment;

Qit: The number of shares listed of the share $i$ at the moment;

$\mathbf{P}_{\mathbf{i o}}$ : The market prices of the stock $\mathrm{i}$ on basis day (original);

i: $1, \ldots \ldots, \mathrm{n}$.

During the session, the HNX-Index will be calculated whenever a share trading is done. So, when the exercise price of each stock transaction changes, the HNXIndex will change over. The HNX-Index reflects price volatility throughout the session and makes online HNXIndex chart. The HNX-Index at the close is the index calculated by the closing price of the shares.

\subsubsection{Factors affecting stock indices}

Stock price is sensitive to the fluctuation of information of socioeconomic system. Such information is considered as factors that affect the stock price. As studied, the factors will be concerned are the stock price movements as endogenous factors, exogenous factors and interference factors.

\subsubsection{Endogenous factors}

The factors that increase or decrease the value of the shares associated with the issuer. Factors are significantly directly affected on the stock value is the value of the company, represented by the profitability on the property of the respective owners with risk level of owner. Besides, the fluctuation of intrinsic factors associated with the issuer has certain impact on the stock price of that company. Specific factors are human factors, technical factors, market and financial situation of the company.

\subsubsection{Exogenous factors}

The stock market is part of the financial market, so it is directly driven by the healthy growth or risk that may occur on financial market. There are some macro-economic factors such as the economic crisis cycle, interest rate, inflation and so on. Other economic factors are disasters and wars.

\subsubsection{Interference factors}

It is the company's dependence on inputs, outputs or financial and currency dependence on another company. If one side (trading partner) is collapsed or in crisis and another side (company) will be collapsed due to the effect of domino effect. Speculative factors, collusion, manipulation of securities by individuals, organizations, domestic or foreign companies create artificial demand and supply of securities and distorted stock price. They are called interfere factors. Besides, the intervention policy of the Government, the internal characteristics of investors are other interfere ones.

In general, factors that affect the stock price volatility include endogenous factors, exogenous factors and interventions. These factors change constantly and continue to interact with each other to form the supply - demand securities on the secondary market. When the stock demand soars and does not meet the supply, the stock price will rise. If the stock demand remains stable and the supply falls down, as a result the stock price will decrease. On the stock market, it can be said that the stock price always changes in accordance with the law of supply and demand - the common rule of the market economy. When the stock market develop stable, endogenous factors are the main factors which influence decisions on the formation and volatility of stock prices.

\subsection{Literature reviews}

Investors on the stock market are very interested in the trading volume of the shares because it can predict stock price changes in the future. The first study of this relationship is presented based on a specified time (contemporaneous relationship) and most of the results indicate that the relationship between the change in share price and trading volume is correlated and vice versa. Therefore, expanding research on the relationship between stock price and trading volume has been receiving special support by financial economists.

Research started first in emerging stock markets. Research of Moosa and Al-Louhani Moosa (1996) pointed out the one-way relationship in the Malaysian market, two-way relationship in the stock market in Singapore and Thailand. However, there is no relationship between price and stocks on the stock market in Philippines. Moreover, Lee and Rui (2000) found the change of stock price and trading volume in the Shanghai and Shenzhen Stock Exchange. For Vietnam's stock market, Loc (2008) suggested that a causal relationship between price and volume of stocks traded does not exist in most cases. There are only a few stocks that demonstrated the correlation. By 2012, the result of Ganger test shows that the change of volume does not affect the 
change of the VN-Index, but in the opposite side, the change of the VN-Index affects the change in trading volume.

As for the European region, the relationship between stock price and trading volume found in the stock markets of Hungary and Poland were studied by Gunduz and Hatemi-J (2005) and the impact of price changes trading volume on the Russian and Turkey markets. Nevertheless, the research on the Czech market showed no relationship between them. Similarly, the developed markets like the US, Japan and Britain were also found the price impact on trading volume in the research Lee and Rui (2002) and Hiemstra and Jones (1984).

This study aims at to test the hypothesis of a causal relationship between stock price and trading volume on the stock market in Hanoi (HNX). Results of this study will be valuable scientific evidence, which helps investors for the reasonable decision. Thereby, this study will contribute to the stability and sustainable development of the Vietnam stock market. The rest of the article is structured as the followings: Section 2 presents the methodology and the description of used data, Section 3 discusses the research results and the final conclusion and recommendations are presented in Section 4.

\subsection{Methodology}

\subsubsection{Used data}

The data used in this study include the HNX-Index chains and stocks traded volume over time with the frequency of the week (weekly series), which were collected during the period from March $5^{\text {th }} 2013$ to March $2^{\text {nd }} 2016$. Price and volume of each stock used were the price and volume of transactions closed on Wednesday in Hanoi Stock Exchange. If Wednesday had no transaction, the closing figures of Thursday (or Tuesday when there is no transaction) would be used. If there was no transaction on Tuesday and Thursday, the data of that week was ignored. Then, based on the closing price per stock, the stock price change (yield) in two consecutive sessions was calculated as follows:

$\mathbf{R}_{\mathrm{t}}=\log \left(\mathbf{p}_{\mathrm{t}}\right)-\log \left(\mathbf{p}_{\mathrm{t}-1}\right)=\log \left(\mathbf{p}_{\mathrm{t}} / \mathrm{t}-1\right)$

Rt: Change of HNX-Index between two consecutive weeks

Pt: The HNX-Index at the closing time on Wednesday at week t

Pt-1: The HNX-Index at the closing time on Wednesday at week t-1

\subsubsection{Methodology}

Granger causality is used to analyze the impact trend of variables in the model. Therefore, Granger is selected to analyze the reciprocating relationship between market index changing and traded shares quantity.

\section{Granger Causality Test:}

Recurrence equation of Granger Test is:

$$
\left\{\begin{array}{l}
Y_{t}=\alpha_{0}+\sum_{l=1}^{k} \beta_{l} Y_{t-1}+\sum_{l=1}^{k} \delta_{l} X_{t-l}+\varepsilon_{t} \\
Y_{t}=\alpha_{1}+\sum_{l=1}^{k} \phi_{l} X_{t-l}+\sum_{l=1}^{k} \rho_{l} Y_{t-l}+v_{t}
\end{array}\right.
$$

If $\delta_{l}$ is not zero but statistically significant, and $\rho_{l}$ is not statistically significant, we conclude that the variation of $\mathrm{X}$ is the cause of the variation of Y (uni-directional causality). If $\delta_{l}$ is not statistically significant, and $\rho_{l}$ is not zero but statistically significant, we conclude that the variation of $\mathrm{X}$ is the cause of the variation of Y (uni-directional causality). If both $\delta_{1}$ and $\rho_{1}$ are not statistically significant, we conclude that $\mathrm{X}$ and $\mathrm{Y}$ are independent from each other.

In this study, $\mathrm{X}$ is the market index and $\mathrm{Y}$ is the volume of shares traded.

Granger Causality Test requires data chain must have stationary. Therefore, before conducting Granger test, unit root tests must be conducted to check the stationary of the data strings.

\section{Unit root test}

In order to conduct unit root test, we use Dickey - Fuller (DF) Test, Augmented Dickey Fuller (ADF) Test or Phillips - Person (PP) Test. ADF Test i processed according to the following steps:

Suppose $Y$ regression under $X$ :

$\mathrm{Y}_{\mathrm{t}}=\beta_{1}+\beta_{2} \mathrm{X}_{\mathrm{t}}+\mathrm{u}_{\mathrm{t}}$

Or:

$\mathrm{U}_{\mathrm{t}}=\mathrm{Yt}-\beta_{1}-\beta_{2} \mathrm{X}_{\mathrm{t}}$

Regression equation has form as Equation (2.1) and gets the remainder $u_{t}$.

Perform unit root tests with the hypothesis $\mathrm{H}_{0}$ (Data is not a stationary proccess) and $\mathrm{H} 1$ hypothesis (data string is a stationary proccess).

Compare the value of tested calculated $t$ with the value of critical $t$ (Expectedin the econometric software) to have test results as the following:

If the value of $|\mathrm{t}|>$ the value of critical $t$, we reject the hypothesis $\mathrm{H}_{0}$. It means that tested data is not a stationary chain.

If the value of $|\mathrm{t}|<$ the value of critical $\mathrm{t}$, we accept the hypothesis $\mathrm{H}_{0}$. It means that tested data is a stationary chain.

We can change a chain which is not stationary into stationary one through different proccess. 


\section{Latency}

According to the nature of the time series, the dependence of variable $\mathrm{Y}$ into a variable $\mathrm{X}$ is rarely simultaneous, but usually after a period of time. That period is called latency. In Granger test, the length of latency is selected based on AIC criteria (Akaike Information criterion). The value $\mathrm{k}$ is selected to have the smallest AIC.

\section{RESULTS AND DISCUSSION}

As presented above, before conducting Granger test, unit root test must be carried out as a prerequisite in order to check the stationary of observed data string. When the observed data string does not have stationary feature, unit root test will continue to be made on the different process of order one. Results unit root test with and without the time trend is shown in the following table:

Table.1: Results of unit root test ADF

\begin{tabular}{lcc}
\hline \multicolumn{1}{c}{ Data chain } & $\begin{array}{c}\text { Without the } \\
\text { time trend }\end{array}$ & $\begin{array}{c}\text { With the time } \\
\text { trend }\end{array}$ \\
\hline HNX-Index value $(\mathrm{k}=1)$ & $-1,13$ & $-2,11$ \\
Stock price's different process of order one (changes & $-7,32^{\mathrm{a}}$ & $-7,32^{\mathrm{a}}$ \\
of HNX-Index between two consecutive sessions) & & \\
$(\mathrm{k}=1)$ & $-4,20^{\mathrm{a}}$ & $-4,46^{\mathrm{a}}$ \\
Trading volume $(\mathrm{k}=1)$ &
\end{tabular}

The testing results of the stationary of HNX-Index and the trading volume suggests that hypothesis about the value chain can not be rejected at a significant level of $5 \%$ because its testingvalue is smaller than respectively critical value. However, when the difference process of order one of the HNX-Index is tested, this hypothesis is rejected at the $5 \%$ significant level. For the chain of trading volume, hypothesis of non-stationary is rejected at the $5 \%$ significant level.

\section{Granger test result}

Based on the results of ADF unit root tests and AIC standard, Granger test is performed to determine the relationship between the change of HNX - Index and the change in the volume of transaction shares. Granger test results are shown in Table 2.

Table.2: Granger test result

\begin{tabular}{lccc}
\hline \multicolumn{1}{c}{ Hypothesis $\mathbf{H}_{0}$} & $\begin{array}{c}\text { F Statistical } \\
\text { values }\end{array}$ & Lag time (k) & Conclusion \\
\hline $\begin{array}{l}\text { Transaction volume will not affect } \\
\text { HXN - Index }\end{array}$ & $3.79^{\mathrm{a}}$ & 2 & Rejected $\mathrm{H}_{0}$ \\
$\begin{array}{l}\text { Change of HNX-Index will not affect } \\
\text { the change of transaction volume. }\end{array}$ & $1.97^{\mathrm{a}}$ & 2 & ${\text { Accepted } \mathrm{H}_{0}}$ \\
\hline
\end{tabular}

a has statistical significance level of $5 \%$

According to the results of testing the hypothesis $\mathrm{H}_{0}$ Granger showed that the volume change does not affect the change of HNX - Index is rejected. According to Granger test, hypothesis $\mathrm{H}_{0}$ shows that the change of transaction volume does not affect the change of HNX - Index is rejected. This means that the change in the volume of transactions affects the change of HNX-Index. In contrast, the hypothesis of change of HNX - Index which will not affect transaction volume can not be rejected at a significant level of $5 \%$. Thus, the relationship between change in the HNX-Index and the transaction volume of the stock is only a one-way relationship.

At the same result with this study, Moos and Al - Loughani (1996) have shown the impact of transaction volume on the stock price on the Malaysian stock market. Similar research on Saatcioglu and Starks (1998) provided evidence for the change in transaction volume which led to a change in the stock price in the stock markets of Brazil and Mexico.

\section{Effect of change of transaction volume to the change of HNX - Index: Result of regression analysis}


Table.3: Effect of change of transaction volume to the change of HNX - Index

\begin{tabular}{lcc}
\hline \multicolumn{1}{c}{ Variables } & $\begin{array}{c}\text { Correlation } \\
\text { coefficients }\end{array}$ & Statistical value t \\
\hline Constant $(\alpha)$ & $-0,122$ & $-2,71$ \\
$\mathrm{R}(-1)$ & $-0,015$ & $-0,18$ \\
$\mathrm{R}(-2)$ & $-0,005$ & $-0,35$ \\
$\mathrm{Ln} \mathrm{V}(-1)$ & 0,003 & 0,84 \\
Ln V(-2) & 0,009 & $2,38^{\mathrm{a}}$ \\
Observation & & 163 \\
$\mathrm{R}^{2}$ adjusted & & 0,03 \\
Statistical value F & & $2,167^{\mathrm{c}}$ \\
\hline
\end{tabular}

a, c statistically significant at 5\%, 10\%

Granger test result shows that the change in the volume of transactions affects the change of HNX - Index. On the basis of this conclusion, we shall determine the degree of influence of the change in transaction volume with HNXIndex by regression analysis. The Granger test result above shows that the change of transaction volume affects the change of HNX - Index.

The regression equation is used:

$\mathrm{R}_{\mathrm{t}}=\alpha+\sum_{i=1}^{2} \beta_{k} R_{t-k}+\sum_{k=1}^{4} \delta_{k} \operatorname{Ln} V_{t-k}+\varepsilon_{t}$

In which:

$\mathrm{R}_{\mathrm{t}}$ : Change of the stock price at $\mathrm{t}$ period

$\mathrm{V}_{\mathrm{t}}$ : Transaction volume at $\mathrm{t}$ period

$\mathrm{k}$ : lag time

Result of regression analysis in the table above shows that the current transaction volume has a proportional relationship to the change of the stock price in 2 sessions later. Particularly, if the volume of stock at time $t$ increases $1 \%$, HNX-Index of 2 session's later will increases $0.009 \%$. The proportional relationship is statistically significant at the $5 \%$ level.

\section{CONCLUSION AND RECOMMENDATION}

\subsection{Conclusion}

This article studies the cause-effect relationship between the change of HNX- Index and the volume of transaction shares on the Hanoi Stock Exchange during the period from 05/03/2013 until 02/03/2016. With Granger causality, the research results indicate that the change of the volume of transaction affects the change of HNX - Index. However, the change of HNX-Index has no influence on the change of transaction volume. Based on the results of this study, we can conclude that the relationship between change of transaction volume and HNX - Index only happens one way from the transaction volume to HNX- Index.

\subsection{Recommendation}

www.ijaems.com
The results of this study have provided information for investors, however in addition to obtained results there are still some drawbacks. Firstly, the sample size (163) is not really big enough. Secondly, this study mainly uses Granger testing method to find out the relationship between the change of transaction volume and HNX- Index. Although Granger testing is being used quite common now, this testing is still limited. That is to perform this test the data chain requires stationarity of data, so for data chain without stationary in unit root test we continue to perform testing for difference process of order one to determine the stationarity of data. However, in fact when first difference of order one is used the nature of the data has changed, and it no longer accurately reflects the true nature of it. So, to overcome this phenomenon the subsequent studies may use Cointergration test. This type of testing does not require data with stationary, so it still retains its true nature.

\section{REFERENCES}

[1] Chen, Gong-Meng, Michael Firth and Oliver M. Rui (2001) The dynamic relation between stock returns, trading volume, volatility, The Financial Review, 38, 153-174.

[2] Lee, Bong Soo and Oliver M.Rui (2002) The dynamic relation between stock return, trading volume: Domestic and cross-country evidence, Journal of Banking and Finance, 26, 51-78.

[3] Lee, Cheng F. and Oliver M. Rui (2000) Does trading volume contain information to predict stock return?Evidence from China's stock markets, Review of Quantitative Finace and Accounting, 14, 341-360.

[4] Moosa, Imad A. and Nabeel E. Al-Loughani (1996) Testing the price-volume relation in emerging Asian stock markets, Journal of Asian Economic, 6, 407-422. 
[5] Gunduz, Lokman and Abdulnasser Hatemi-J (2005) Stock price and volume relation in emerging markets, Emerging Markets Finance and Trade, 41, 29-44.

[6] Hiemstra, Craig and Jonathan D. Jones (1994) Testing for linear and nonlinear Granger causality in the stock price-volume relation, Journal of Finance, 49, 16391664

[7] Saatcioglu K and Starks L (1998), 'The Stock PriceVolume Relationship in Emerging Stock Markets the case of Latin America', International Journal of Forecasting, 14, 215-225.

[8] Mai Van Nam, Pham Le Thong, Le Tan Nghiem and Nguyen van Ngan, 2004. The econometrics. Ho Chi Minh ctity, Statistical Publication.

[9] Truong Dong Loc, 2008. The causual relationship between stock price and stock quanlity traded. Banking Technology Journal, 38, pages 32-37.

[10] Truong Dong Loc and Tran Van Vu, 2012. The relationship between price index and stock quanlity traded at Ho Chi Minh Stock Exchange. Proceeding Sciences, Papes 133-143. 